\title{
The Medical Termination of Pregnancy (Amendment) Act, 2021: A step towards liberation
}

\author{
VERONICA ARORA, ISHWAR C VERMA
}

\begin{abstract}
Reform of the abortion laws in favour of the well-being of pregnant women is one aspect of the removal of gender discrimination. The Medical Termination of Pregnancy Act (MTP Act) 1971, was a breakthrough legislation in this regard, as it reduced the number of unsafe illegal abortions. With advancements in ultrasonography and genetic technologies, many foetal malformations and genetic disorders were being diagnosed after 20 weeks of gestation. The fact that termination of pregnancy was not legally permitted beyond 20 weeks of gestation caused great distress to such women, and highlighted the need to increase the upper limit of termination of pregnancy. Concurrently, there has been greater awareness around the world on the rights of women to take decisions regarding their own bodies. The MTP Bill, 2020, has come as a breath of fresh air extending the term limit for legal abortions to 24 weeks for certain categories of women, and removing the limit for abortion in the presence of a significant foetal abnormality. The amendments were recently approved by Parliament and the President of India, and have become law as of March 25, 2021. This paper presents the amendments made and their implications for obstetric, ultrasonographic and foetal medical practice. It also presents a critique of the various Acts and suggests further amendments that would enhance the value of the Act.
\end{abstract}

Keywords: MTP, amendments, MTP Act 2020, foetal malformations, Indian Parliament, abortion laws

\section{Introduction}

The laws with regard to abortion vary in different countries, as they represent an interaction of society, religion, law and

Authors: Veronica Arora (Veronicaarora@gmail.com), Associate Consultant, Institute of Medical Genetics and Genomics, Sir Ganga Ram Hospital, New Delhi.110 060 INDIA; Ishwar C Verma (corresponding author - icverma@gmail.com), Professor, Senior Consultant and Adviser, Institute of Medical Genetics and Genomics, Sir Ganga Ram Hospital, New Delhi.110 060 INDIA.

To cite: Arora V, Verma IC. The Medical Termination of Pregnancy (Amendment) Act, 2021: A step towards liberation. Published online first on May 10, 2021. DOI: 10.20529/IJME.2021.036.

Manuscript Editor:Veena Johari

(c) Indian Journal of Medical Ethics 2021 the rights of women. Article 15 of the Indian Constitution lays down that the state shall not discriminate against any citizen on the grounds of sex (1). Despite this, discrimination against women is widespread in India and has existed from time immemorial. To do away with this discrimination, action is required on many fronts - social, economic and legal. The modification of the abortion laws in favour of the health and well-being of women is one aspect of this reform. In this paper, we trace the history of abortion laws in India starting from the MTP Act of 1971(2), its revision in 2002 (3), continuing into the Medical Termination of Pregnancy (Amendment) Bill, 2020 (4), and its publication in the Gazette of India as The MTP Amendment Act 2021, no.8 of 2021 on March 25, 2021 (5). We examine the various sections of the MTP Amendment Act, 2021(hereinafter, MTP Act, 2021) and show how it will strengthen the rights of women, and will inevitably improve the practice of obstetrics, ultrasonography and foetal medicine. We also suggest further changes that would improve it from the human rights perspective.

\section{The pre-MTP era}

In 1860, the Indian Penal Code (IPC) (6) was enacted by the British colonial government. Sections 312-316 of the IPC declared that "inducing an abortion amounted to culpable homicide, and that any person performing it would be subject to imprisonment for three or more years and/or payment of a fine". The only exception to this was if the abortion was performed to save the life of the woman. This penal code was changed in Britain in 1967, but ironically, not in India until 1971. Countless women died as a result of unsafe illegal abortions due to the existence of this penal code (7-10). It was the combination of this high mortality and the pressure of an increasing population that made the government reconsider the prevailing law in 1971 by enactment of an Act.

\section{The MTP Act, 1971: Benefits and challenges}

The MTP Act of 1971 (2) stated that "a pregnancy may be terminated on the advice of one registered medical practitioner if the length of the pregnancy does not exceed twelve weeks; or on the advice of two medical practitioners if length of the pregnancy exceeds twelve weeks but does not exceed twenty weeks." This Act extended the indications for termination of pregnancy, specified the place of termination and the training of the person performing it. The MTP Act, 1971, was amended in 2002 to allow termination of 
pregnancy up to 20 weeks of gestation, to facilitate better and more universal implementation and increased access for women, especially in the rural areas (3).

However, the Act did not keep up with the advances in technology in diagnosing the health of the foetus and in obtaining an abortion for an unwanted or abnormal foetus (11). Singh and colleagues reported that about 15.6 million abortions took place in India in 2015, of which $73 \%$ were performed outside the healthcare facilities (12).

\section{Need for amendment}

With the passage of time and advancement in medical technologies such as ultrasonography and genomics, the MTP Act of 1971 became outdated and inadequate as a safeguard for the rights of women and their families. A few cases are presented below to illustrate some challenges to the adequacy of the Act. Cases 2 and 3 are from the practice of the authors, while the rest are from published literature.

\section{Illustrative cases}

1. Foetus with Down syndrome In 2017, family X. was denied permission to abort a foetus having Down syndrome at 26 weeks of pregnancy, because the 20-week mark had been crossed (13). The family already had a child with special needs, and was not in a position to care for another child with developmental delays and medical problems. Denial of termination of pregnancy caused additional distress to the family and generated mistrust in the judicial system. A well-formulated Act, initially ahead of its time, had not kept pace with technology and needed to be revised.

2. Foetus with abnormal cerebral ventricles A couple with a history of two miscarriages sought consultation at 19 weeks of pregnancy for a foetus with both cerebral ventricles of borderline size. Three weeks later the ventricles enlarged further to reach an abnormal range. Genetic testing showed the foetus to have a chromosomal abnormality. The couple desperately wanted to discontinue the pregnancy due to lack of funds to support a child with special needs, but no obstetrician was willing to terminate the pregnancy. The woman went on to deliver a child with multiple malformations, global developmental delay and autistic features

3. Genetic disorders detected in the 3rd trimester Some disorders such as achondroplasia, primary microcephaly or lissencephaly (a smooth surface of the brain) are detectable only in the third trimester. Couple B. presented with a history of two neonatal deaths due to microcephaly, seizures and retarded growth. The woman attended a clinic at 19 weeks of pregnancy with a normal ultrasound scan. She was told that diagnosis of microcephaly at this stage of pregnancy was only possible if the causative molecular changes were known. In the absence of such knowledge, the only alternative would be to follow foetal head growth by ultrasound after three weeks. But this would be too late for termination. She took a chance, but unfortunately on ultrasound study, the foetus was detected to have icrocephaly and suffered the same fate as its siblings.

4. Appeals to the court by rape survivors The NGO Pratigya-Campaign for Gender Equality and Safe Abortion examined 194 cases of rape survivors that appeared between June 1,2016, and April 30, 2019 , before the Supreme Court $(n=21)$ and various High Courts $(n=173)$ seeking permission to terminate pregnancies (14). The High Courts rejected pleas by rape survivors in 29 cases this was despite previous instances where judgments applied the provisions of the MTP Act, 1971, to mean that the mental and physical trauma caused to a sexually assaulted woman was considered a grave threat to her life.

\section{The MTP (Amendment) Act, 2021: Provisions}

As time elapsed, advances in technology occurred both in ultrasonography and genetics, enabling prenatal diagnosis of a large number of foetal disorders. For various scientific and biological reasons, diagnosis of a foetal anomaly is often made after 20 weeks of gestation and this underscores the need for raising the upper gestational limit for terminating pregnancies. In view of the steady increase in writ petitions seeking termination of pregnancy in cases of severe foetal abnormalities, the concerned medical professionals have been representing to the Ministry of Health and Family Welfare to amend the MTP Act and bring it in line with international thinking (11). Therefore, the MTP Act, 2021, which has now become law (5), contains significant amendments to the MTP Act of 1971. These amendments will liberate pregnant couples from the restrictions on late-term termination of pregnancies and allow foetal medicine, obstetrics and reproductive medicine practitioners sufficient time to make accurate diagnoses of foetal anomalies.

\section{Key provisions}

Some important sections of the Act:

Section 3 states that: "a pregnancy may be terminated by a registered medical practitioner - (a) where the length of the pregnancy does not exceed twenty weeks", if such medical practitioner is "of the opinion, formed in good faith, that (i) the continuance of the pregnancy would involve a risk to the life of the pregnant woman or of grave injury to her physical or mental health; or (ii) there is a substantial risk that if the child were born, it would suffer from any serious physical or mental abnormality." Where "(b) the length of the pregnancy exceeds twenty weeks but does not exceed twenty-four weeks, in case of such category of woman as may be prescribed by rules made under this Act, not less than two registered medical practitioners" have to opine as 
stated above.

Two explanations to clauses (a) and (b) are included in the MTP Act, 2021:

Explanation 1: For the purposes of clause (a), where any pregnancy occurs as a result of failure of any device or method used by any woman or her partner for the purpose of limiting the number of children or preventing pregnancy, the anguish caused by such pregnancy may be presumed to constitute a grave injury to the mental health of the pregnant woman."

Explanation 2: For the purposes of clauses (a) and (b), where any pregnancy is alleged by the pregnant woman to have been caused by rape, the anguish caused by the pregnancy shall be presumed to constitute a grave injury to the mental health of the pregnant woman.

Most importantly, Section 3, subsection (2B) states that; The provisions of sub-section (2) relating to the length of the pregnancy shall not apply to the termination of pregnancy by the medical practitioner where such termination is necessitated by the diagnosis of any of the substantial foetal abnormalities diagnosed by a Medical Board.

Section 3, subsection (2A) clarifies that:

The norms for the registered medical practitioner whose opinion is required for termination of pregnancy at different gestational ages shall be such as may be prescribed by rules made under this Act.

Sub-section (2C) directs that:

Every State Government or Union territory, as the case may be, shall, by notification in the Official Gazette, constitute a Board to be called a Medical Board for the purposes of this Act to exercise such powers and functions as may be prescribed by rules made under this Act.

The Board may be constituted "as may be notified in the Official Gazette by the State Government or Union territory, as the case may be."

Section 5A of the MTP Act, 2021, subsection (1), emphasises that:

No registered medical practitioner shall reveal the name and other particulars of a woman whose pregnancy has been terminated under this Act except to a person authorised by any law for the time being in force." Whoever contravenes the provisions of the above sub section "shall be punishable with imprisonment which may extend to one year, or with fine, or with both."

\section{Discussion}

The extension of the time limit for termination of pregnancy in the Act are welcome. However, taking a humanitarian view, these provisions should have been applied to all women but have not, as the extension from 20 to 24 weeks is only applicable to special categories of women as prescribed by rules under this Act. However, the categories to whom this Act would apply are fairly widely applicable, eg the clause that "women in whom the continuation of the pregnancy would involve a risk to the life of the pregnant woman or of grave injury to her physical and mental health" would cover many situations. Similarly, the clause "women who have a pregnancy as a result of the failure of any device or method used by the woman or her partner for limiting the number of children or preventing pregnancy, the anguish caused by such pregnancy may be presumed to constitute a grave injury to the mental health of the pregnant woman" would apply to many situations requiring an abortion.

A far-reaching amendment is that in case of any substantial foetal anomaly, the upper limit of termination shall not apply to the termination of pregnancy, where such termination is necessitated by the diagnosis of any of the substantial foetal abnormalities, by a Medical Board, as specified in the Act. This is a desirable clause, but there should have been a proviso for quick and timely decisions by the board.

There is little doubt that this amendment, by advancing the upper limit of termination of pregnancy has provided great relief for women who require an abortion. Many organisations and experts have argued that the amendment does not go far enough in recognising the autonomy of the woman to decide whether to continue or discontinue her pregnancy (15). One view is that the Amendment takes a medical approach rather than a humanitarian one towards the issue of abortion.

For abortion up to 20 weeks of pregnancy, only the approval of one registered medical practitioner is required. Earlier, a registered medical practitioner could approve abortion only up to 12 weeks of gestation. This would imply that the obstetrician of the pregnant woman is readily available to approve abortion and support the mother in taking the appropriate decision. For termination up to 24 weeks, the second medical practitioner could well be the foetal medicine specialist or the ultra-sonographer or a senior obstetric colleague. Some members of Parliament argued that there is already a shortage of doctors in rural areas and there would be difficulty in getting the necessary nod from a second medical practitioner, which would entail hardship for the women (15). The parliamentarian, Varun Gandhi, suggested that training may be given to practitioners of Ayurveda and homeopathy to ease the situation in rural areas (15).

Some members of non-governmental organisations have expressed apprehensions regarding fixing the upper limit for abortion in cases of rape (15). They point out that there are procedural delays at police stations as well as the courts, and feel that there should have been further relaxation of the upper limit.

The greatest beneficiaries of the amendments would be couples who are worried about having a baby suffering serious physical or mental abnormalities. While the new MTP 
Act has done away with the upper limit for termination of pregnancy when a substantial foetal abnormality is involved, some experts have suggested that the word "substantial" should have been defined more precisely. Still, the amended Act will provide the obstetrician and the foetal medicine specialist time to carry out tests for the diagnosis of abnormalities.

Now that the MTP Amendment Act has become law in the country, it will enable India to join the progressive group of nations that recognise the right of women to take autonomous decisions about their pregnancies. Although it falls short in upholding the unfettered rights of women over their own bodies, the MTP (Amendment) Act, 2021, is definitely a step in the right direction.

Conflict of interest: None declared.

\section{Author contributions: Both authors contributed equally}

\section{References}

1. Ministry of Law and Justice, Govt of India. The Constitution of India, as on 9th December, 2020. New Delhi; MoLJ; 2020 [cited 2021 Feb 22]. Available from http://legislative.gov.in/ sites/default/files/coi-4 March2016.pdf

2. Ministry of Health and Family Planning, Govt of India. The Medical Termination of Pregnancy Act (Act No. 34, 1971). New Delhi: Government of India, 1971[cited 2021 Feb 22]. https:// www.tcw.nic.in/Acts/MTP-Act-1971.pdf

3. Ministry of Health and Family Welfare, Government of India. The Medical Termination of Pregnancy Amendment Act 2002 (No. 64 of 2002). New Delhi: MoHFW; 2002 Dec [cited 2021 Feb 22]. Available from: https://main.mohfw.gov.in/acts-rules-and-standards-healthsector/acts/mtp-act-amendment-2002

4. Ministry of Health and Family Welfare, Govt of India. The Medical
Termination of Pregnancy (Amendment) Bill, 2020, (Bill No 55 of 2020). New Delhi: MoHFW; 2020 [cited 2021 Feb 22\} Available from: http://164.100.47.4/BillsTexts/LSBillTexts/PassedLoksabha/55C_2020_LS_Eng.pdf

5. Ministry of Law and Justice, Govt of India.. The Medical Termination of Pregnancy (Amendment) Act 2021, no 8 of 2021. The Gazette of India. CG-DL-E-26032021-226130. March 25, 2021.

6. Ministry of Home Affairs, Government of India. The Indian Penal Code, 1860. New Delhi: MoHA; 1860 [cited 2021 Feb 22]. Available from: https://ncib.in/pdf/indian-penal-code.pdf

7. Chhabra R, Nuna S. Abortion in India: an overview. New Delhi: Veerenda Printers, 1994.

8. Duggal R, Ramachandran V. The abortion assessment project - India: key findings and recommendations. Reprod Health Matters. 2004; 12 (24 Suppl): $122-9$

9. Sedgh G, Bearak J, Singh S, Bankole A, Popinchalk A, Ganatra B, et al. Abortion incidence between 1990 and 2014: global, regional, and sub-regional levels and trends. Lancet. 2016;388: 258-67.

10. Khanna AK, Prabhakaran A, Patel P, Ganjiwale JD, Nimbalkar SM. Social, psychological and financial burden on caregivers of children with chronic illness: a cross-sectional study. Indian J Pediatr. 2015 Nov; 82(11):1006-11.

11. Royal College of Obstetricians and Gynaecologists. The care of women requesting induced abortion. (Evidence-based Clinical Guideline No 7). London: RCOG; 2011 Nov 23 [cited 2018 Sep 6]. Available from: https://www.rcog.org.uk/globalassets/documents/ guidelines/abortion-guideline_web_1.pdf

12. Singh S, Shekhar C, Acharya R, Moore AM, Stillman M, Pradhan MR, et al. The incidence of abortion and unwanted pregnancy in India 2015. Lancet Global Health. 2018 Jan 1; 6(1): e111-120.

13. Nimbalkar SM, Patel DS. The Medical Termination of Pregnancy Act: Need to keep pace with technology. Indian J Med Ethics. 2019 JanMar; 4(1):59-64. Doi:10.20529/IJME.2018.096

14. Ghoshal A. Women forced to approach courts to terminate pregnancies within legal 20-week limit, says Study. News18.com. 2019 Oct 1 [cited 2020 Aug 12]. Available from: https://www.news18.com/news/india/permission-to-abort-womenforced-to-approach-courts-to-terminate-pregnancies-within-legal20-week-limit-2329037.html

15. Pyne S, Nagpal A, Barua A. Lok Sabha debates on MTP (Amendment) Bill 2020. 2020 Mar 27[cited 2020 Apr 18]. Available from: https:// safeabortion889409100.wordpress.com/2020/03/27/lok-sabhadebate-on-mtp-amendment-bill-2020/ 